\title{
MODELO TERMOGRÁFICO DE DETECÇÃO DE COLAMENTO DE AÇO NO MOLDE NOS LINGOTAMENTOS CONTÍNUOS DA ARCELORMITTAL TUBARÃO*
}

\section{Resumo}

Altemar Dettogne do Nascimento ${ }^{1}$ Sandro de Souza Santos ${ }^{2}$ Alexandre Aparecida Morais ${ }^{3}$

Rogério Luiz Fracalossi ${ }^{4}$ Antônio Luiz Gomes Reis ${ }^{5}$

O colamento de aço no molde (sticker) é uma anomalia de processo de lingotamento, que quando não detectado pelos modelos de prevenção de sticker, pode gerar breakout, o que significa perdas de produção significativas e aumentos de custos de manutenção para recuperação de componentes de segmentos e moldes, além dos riscos de segurança durante a limpeza do aço dentro da máquina e reprocessamento das placas para eliminação de defeitos superficiais. Outro aspecto a ser considerado é a ocorrência de falso alarme de sticker que também gera custos adicionais de produção, aumento de defeitos superficiais nas placas e powder slivers em laminado a quente devido a redução brusca da velocidade de lingotamento.

Visando reduzir as ocorrências citadas acima e otimizar o processo de lingotamento, um novo sistema de detecção de sticker foi implantando, em AM Tubarão, nas 03 máquinas de lingotamento contínuo de placas, com uma configuração diferente da que que habitualmente é encontrada no mercado. O sistema é baseado em dois eixos: uma imagem termográfica do molde e um sistema de cálculo bastante avançado. Este trabalho apresenta os resultados deste processo e os ganhos obtidos quanto à redução de alarme falso de sticker.

Palavras-chave: Sticker; Termografia.

\section{THERMOGRAPHY MODEL TO MOULD STICKER DETECTION AT SLAB CASTERS OF THE ARCELORMITTAL TUBARÃO}

\begin{abstract}
Sticker is a casting anomaly, and when not detected by prediction models it generates a breakout and consequently significate production losses and maintenance costs increase to repair damaged equipment. Also there are safety issues during the cleaning of the burrs from breakouts and reconditioning of slabs due to superficial defects. Another aspect to be considered is the occurrence of false alarm which also generates additional production costs, slabs superficial defects and powder slivers in hot coils due to fast ramp of the casting speed.

Aiming to reduce the occurrences mentioned above and optimizes the casting process the new detection system was implemented on three casters and it is very different from what is found on the market. The system is based on 2 pillars: thermographic images of the mold and a very advanced calculation system. This paper presents the results of this process and gains due to reduction of false alarms.
\end{abstract}

Keywords: Sticker; Thermography.

1 Mestre em Engenharia de Materiais, Especialista Sênior de Lingotamento Contínuo Lingotamento Contínuo da ArcelorMittal Tubarão, ES, Brasil. altemar.dettogne@arcelormittal.com.br

2 Mestre em Engenharia de Materiais, Gerente de Divisão Técnica da ArcelorMittal Tubarão, ES, Brasil. Membro da ABM, sandro.santos@arcelormittal.com.br

3 Mestre em Engenharia de Materiais, Especialista Sênior de Lingotamento Contínuo da ArcelorMittal Tubarão, Vitória, ES, Brasil. Membro da ABM, E-mail: alexandre.aparecida@arcelormittal.com.br.

4 Engenheiro Elétrico da Área de Lingotamento Contínuo da ArcelorMittal Tubarão, ES, Brasil. E-mail: rogerio.fracalossi@arcelormittal.com.br.

5 Engenheiro Elétrico da Área de Engenharia da ArcelorMittal Tubarão, ES, Brasil. E-mail: antonio.Ireis@arcelormittal.com.br 


\section{INTRODUÇÃO}

A ArcelorMittal Tubarão (AMT) iniciou sua operação em Novembro de 1983, e se caracteriza pela produção de placas de aço via lingotamento contínuo e laminado a quente. A primeira máquina de lingotamento contínuo, com capacidade nominal de 1,8 milhões de t / ano, entrou em operação, em Abril de 1995, tendo como objetivo aumentar a sua competitividade e atender melhor aos requisitos dos clientes, quanto à qualidade do produto.

Em Fevereiro de 1998 a AMT iniciou a operação de sua máquina de contínuo oㅜ 2, tipo vertical curva, dotada de várias tecnologias, simultaneamente com a desgaseificação a vácuo $\mathrm{RH}$ (1 semestre de 1998), visando o enobrecimento da linha de produtos.

Em 2002 iniciou-se a produção de laminados a quente com a implantação do hot strip mill (HSM) com tecnologia state-of-the-art visando atender as demandas dos principais mercados.

Novos equipamentos foram implantados na usina a partir de 2004 desde a área de redução até Aciaria demandando investimentos na ordem de US\$1.8 bilhões, sendo $12 \%$ alocados para controle ambiental. Entre os equipamentos instalados vale à pena destacar o terceiro alto forno, o terceiro convertedor, o segundo $\mathrm{RH}$ e a terceira máquina de lingotamento contínuo. A figura 1 mostra o fluxo atual de produção (1). Em 2007 ocorreu o start up destes novos equipamentos aumentando a capacidade nominal da usina para 7,5 milhões de tonelada de placa.

Utilizando a metodologia de melhoria contínua no processo produtivo e manutenções em conjunto com tecnologias avançadas, foi atingido a marca histórica de produção de placas de $7.034 \mathrm{Mt}$ em 2016.

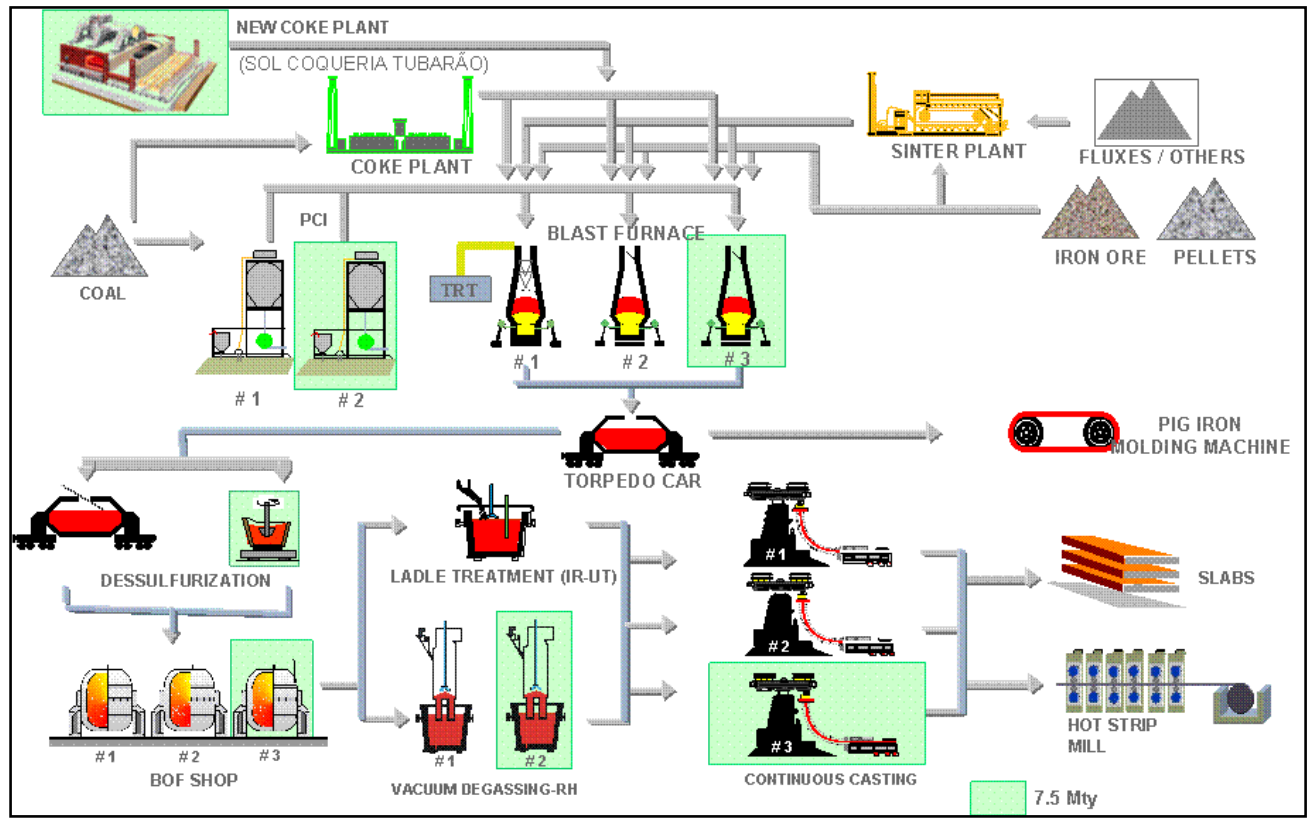

Figura 1. Fluxo de produção da ArcelorMittal Tubarão

No processo de lingotamento contínuo, durante a solidificação do aço dentro do molde, ocorre em alguns casos, aderência da camada de aço solidificada à placa de cobre do molde. Isto gera um "rasgo" implicando em deformação indesejável do sólido produzido (placa, tarugo, billet, etc), este fenômeno é conhecido como 
colamento (sticker), que quando não detectado pode gerar o rompimento da pele na saída do molde. O sticker na superfície da placa, figura 2, pode ser detectado através de um sistema termográfico a partir de termopares instalados internamente ao molde e com monitoramento constante das temperaturas que são analisadas através de software específico. Quando este fenômeno é detectado, a velocidade de lingotamento é reduzida, aumentando o tempo de residência do aço no molde, visando o aumento da espessura de pele solidificada e garantir a solidificação do "rasgo da shell" ainda dentro do molde, evitando o rompimento da pele (2).

O novo sistema termográfico, para detecção de sticker, implantando nas 03 máquinas da AMT Tubarão, possui dois eixos: uma imagem termográfica do molde e um sistema de cálculo bastante avançado. Este trabalho apresenta os resultados deste processo e os ganhos obtidos quanto à redução de alarme falso de sticker.

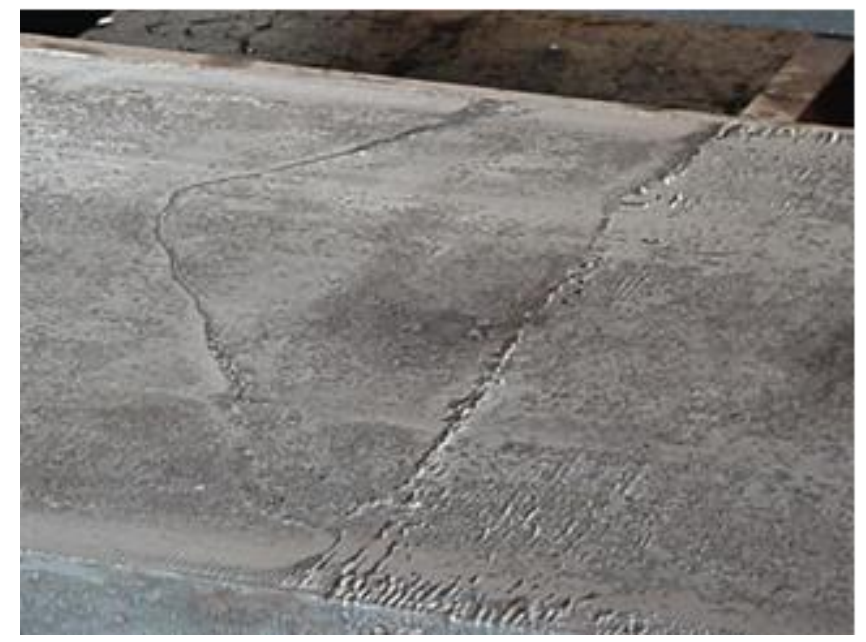

Figura 2. Foto ilustrativa mostrando o defeito na placa ocasionado por sticker.

\section{MATERIAIS E MÉTODOS}

A figura 3 demonstra a sequencia de propagação de agarramento de aço no molde, através dos steps de "a" a "e".

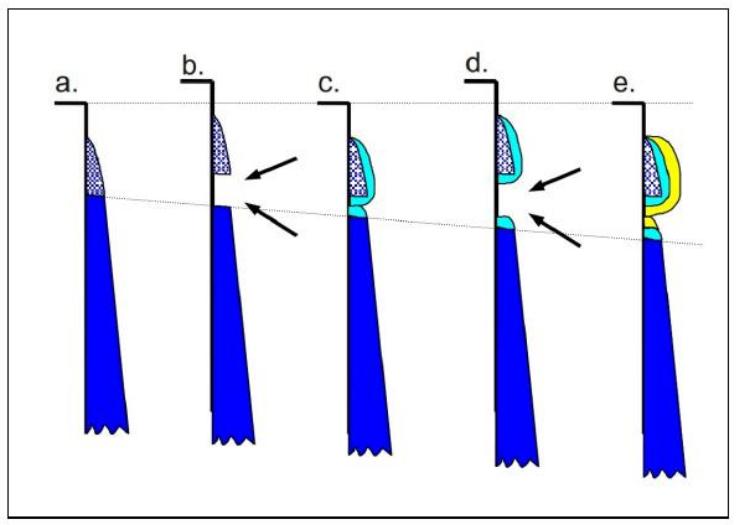

Figura 3. Sequência de agarramento de aço no molde - steps de "a" a "e" 


\section{Step a.}

Simboliza o inicio de formação do sticker no molde. O fenômeno do sticker sempre inicia a partir do topo do molde na região do meniscus. A zona solidificada irá agarrar na placa de cobre sendo que parte da shell irá extrair normalmente.

As causas de sticker são várias que podem ser de processo, materiais e composição química do aço. O sticker é mais frequente em aços peritéticos devido as reações durante a solidificação, o que pode ser explicado pela redução volumétrica que ocorre na transformação da fase $L$ (líquida) $+\delta$ (ferrita,ccc) para o ferro $\gamma$ (austenita,cfc), o que gera o deslocamento da "pele" formada em relação a parede do molde. Esta perda de contato dificulta a transferência de calor, o que ocasiona um reaquecimento local desta área, gerado um decréscimo dada resistência e um retardo no crescimento da pele sólida. Quando se aplica uma tensão sobre esta área a pele fina e frágil, pode cisalhar e trincar gerando o sticker. A figura 4 mostra três etapas tendo como exemplo a reação peritética. $\mathrm{Na} 1^{1}$ a etapa, figura $4(\mathrm{a})$ em altas taxas de resfriamento, "ilhas" de cristais $\delta$ aparecem; 1/30 segundos após, figura 4(b), cristais de $\delta$ transformam-se em $\gamma$. Na $3^{\text {a }}$ etapa, figura 4(c) após a completa solidificação ( 2 segundos) é possível verificar que este cristal $\gamma$, formado, possui irregularidades superficiais, atribuídas às contrações volumétricas decorrentes da reação ${ }^{(2)}$.
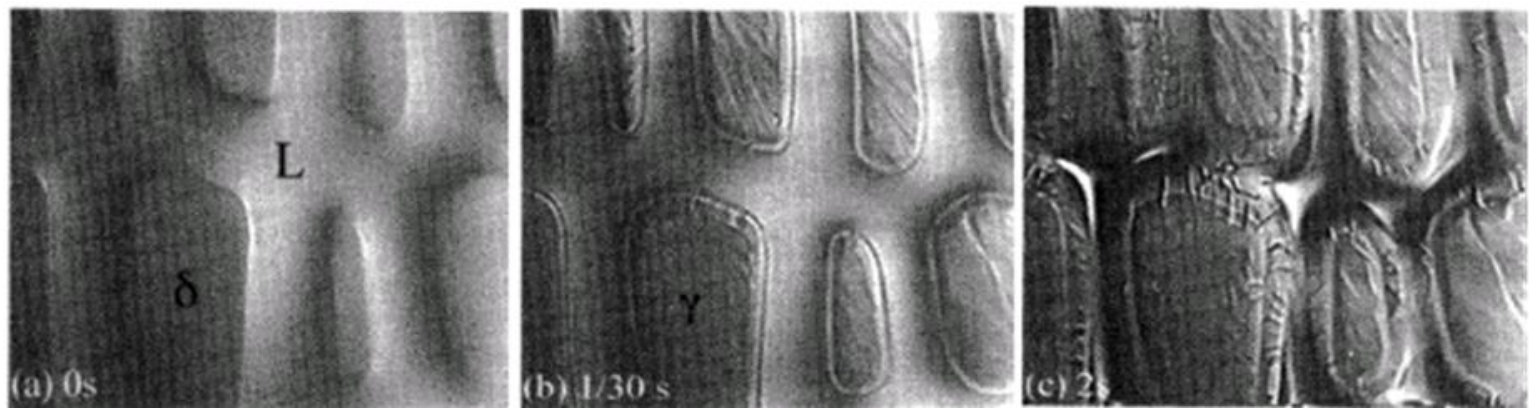

Figura 4 - (a) Base formação, (b) Coexistência de $L+\delta \rightarrow \gamma$; (c) Reação peritética a transformação do Fe- $0,14 \%$ de carbono durante solidificação a $1495 \stackrel{\circ}{C}$

\section{Step b.}

O step (b) mostra a parte da shell aderida ao molde que se moveu para cima com o deslocamento do oscilador do molde. O rasgo da shell aparece logo abaixo e o aço líquido irá preenchê-lo (representado pelas 2 setas).

\section{Step c.}

A parte da shell aderida moveu-se para baixo com o molde, porém a placa também foi para baixo. Portanto, o rasgo não pode ser completamente fechado.

\section{Step d.}

Parte da shell aderida ao molde está subindo novamente com o deslocamento do oscilador e novo rasgo será criado na parte mais fraca da shell e novamente o aço líquido irá preencher este rasgo.

\section{Step e.}

O step (e) é um deslocamento ou intensificação do step (c), enquanto o rasgo se move para baixo. Teoricamente, é possível mostrar que o rasgo move no mínimo com $50 \%$ da velocidade de lingotamento. Uma vez que o rasgo deixa o molde não ocorre à solidificação do aço e consequentemente o breakout. A combinação da 
propagação da solidificação com o efeito do sticker irá gerá um efeito tipo "V" na placa.

\section{1 - Efeito do sticker nos termopares instalados no molde}

A figura 5 apresenta os três steps $(\mathrm{a}, \mathrm{b}, \mathrm{c})$ onde o sticker passa em frente aos termopares instalados no molde. Observa que existe um padrão de subida e descida da temperatura detectada pelor termopar superior $e$ inferior quando do deslocamento do rasgo da pele no sentido de lingotamento. Este comportamento de temperatura é a base para desenvolvimento do software de detecção de sticker.
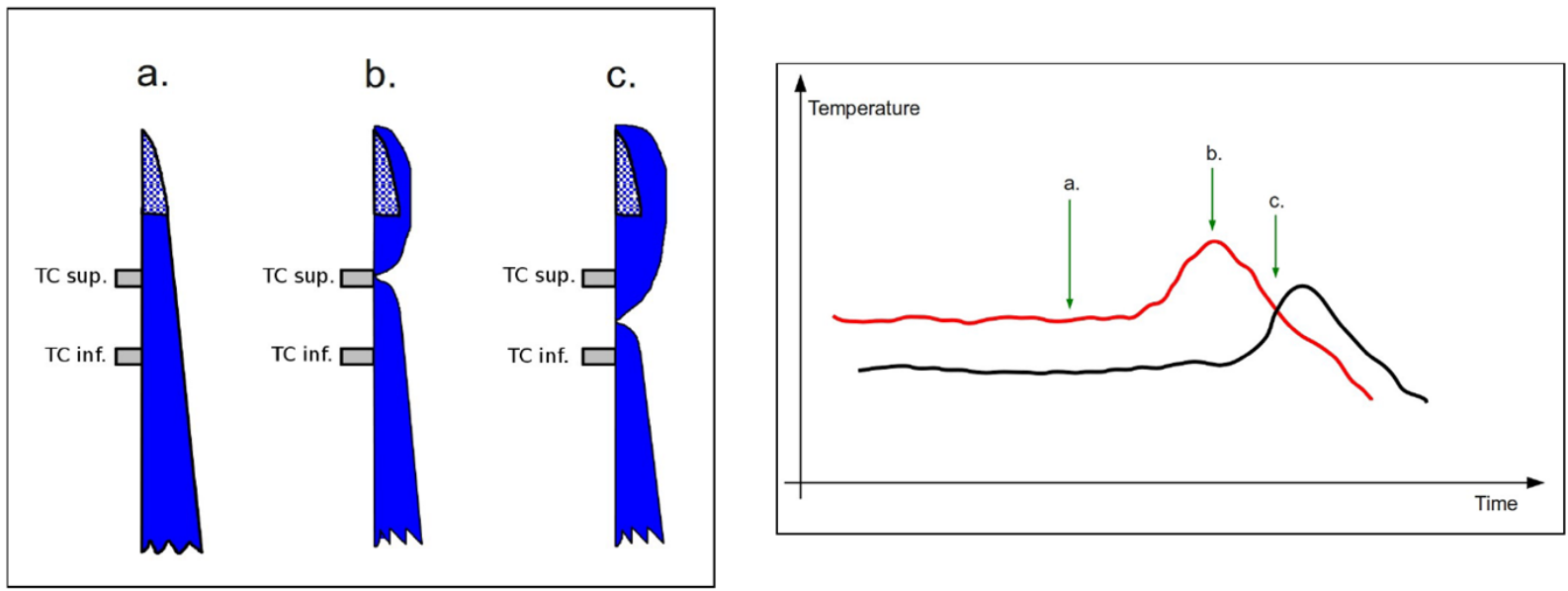

Figura 5. Efeito do sticker nos termopares instalados no molde. Fonte EBDS Engineering

\section{2 - Estratificação da origem dos breakouts}

A figura 6 demonstra que $25 \%$ da origem dos breakouts, em 2015, foram devidos a stickers não detectados. Também se destaca neste período, mas sem demonstração gráfica, a elevada frequência de alarme falso de sticker impactando nos índices de qualidade da placa.

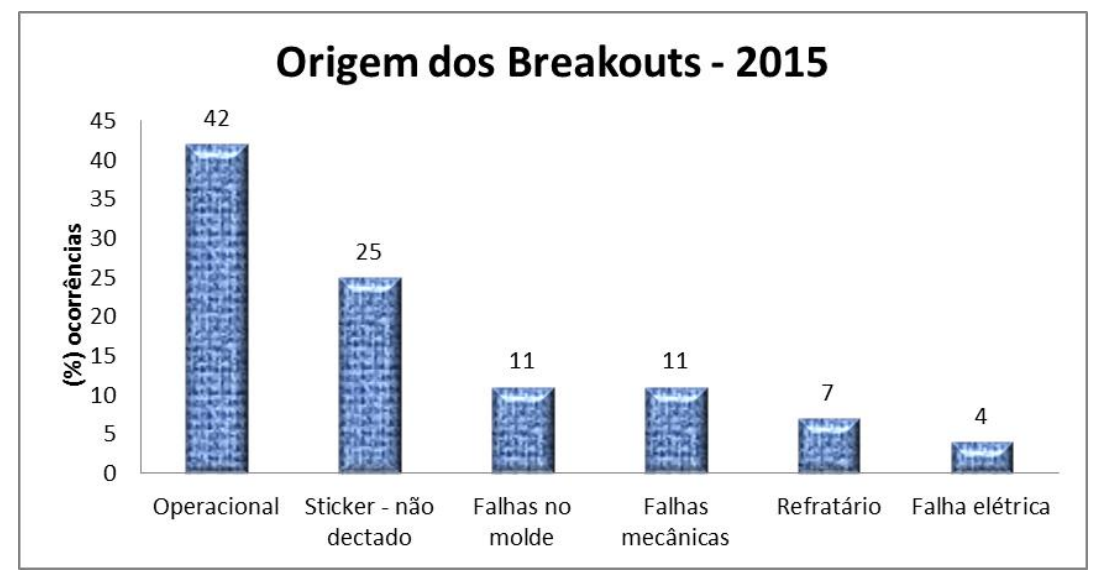

Figura 6. Estratificação da origem dos breakouts - 2015. ArcelorMittal Tubarão 
No segundo semestre de 2015 foi realizado um benchmarking de tecnologias, para detecção de sticker, levando em consideração a interface visual do fenomeno de agarramento da shell no molde, como também, a eficiência de detecção. A figura 7 demonstra os dois tipos de tecnologias existentes no mercado quanto à apresentação visual: gráfica (a) e termográfica (b).
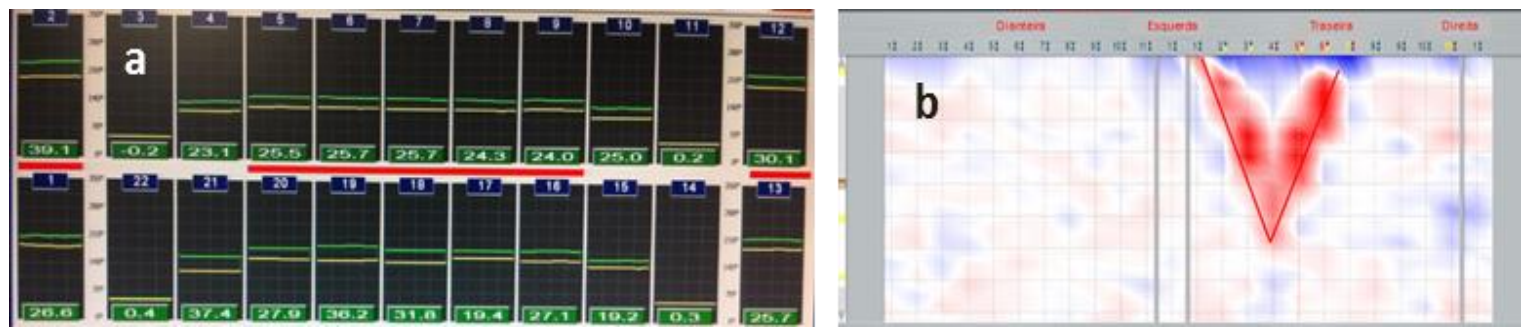

Figura 7. Apresentação visual de detecção de sticker: (a) - gráfica; (b) - termográfica.

\section{3 - Modelo termográfico de detecção de sticker}

O sistema de detecção de sticker é baseado em dois eixos: uma imagem termográfica do molde, e um avançado sistema de cálculo. A imagem representa as quatro faces de cobre do molde. Ela exibe em tempo real todos os eventos térmicos da placa recém-formada "no interior do molde", de maneira a revelar eficientemente qualquer evento irregular ao operador. Por exemplo, no caso de perfuração por colamento a conhecida forma em "V" irá aparecer (figura 8).

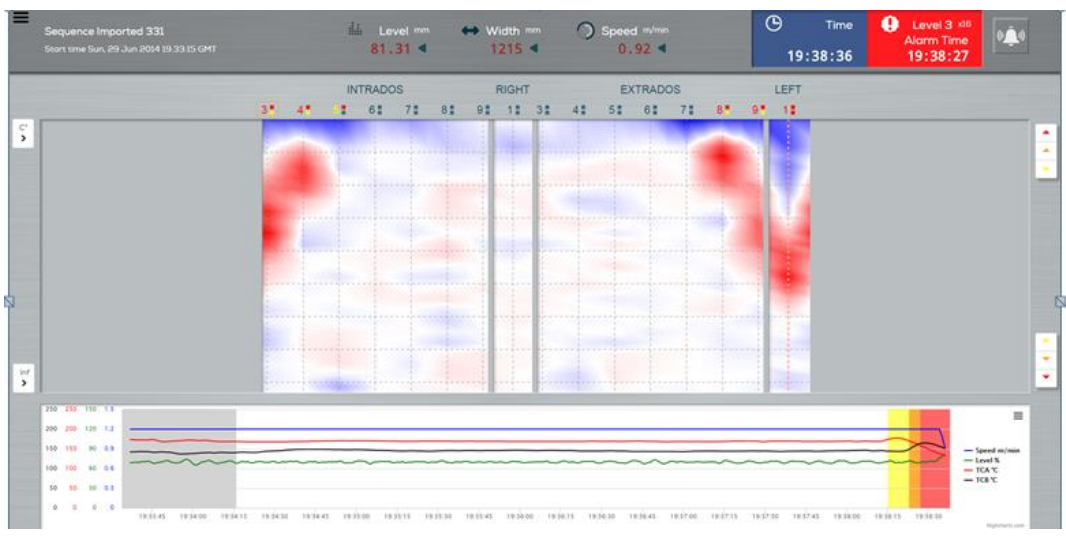

Figura 8. Termografia do sticker.

Os cálculos são baseados nos possíveis comportamentos metalúrgicos das curvas. Isto permite detectar não só os colamentos, como também, outros fenômenos. 0 sistema é "auto ajustável" às condições de lingotamento, de maneira que não se faz necessária a pré-seleção do tipo de aço (3). A junção da análise visual por termografia, e com vários níveis de alarmes, possibilita o operador a tomar decisões preventivas no processo para evitar a ocorrência do sticker ou até mesmo o Breakout. 
Principais características do Software:

$\checkmark$ Auto-adaptação às condições de lingotamento sem qualquer intervenção necessária de um operador graças aos seus parâmetros Individuais de ajuste de auto-Adaptação independente da composição química do aço;

$\checkmark$ Quantificação da importância dos fenômenos para aumentar a confiabilidade e a velocidade de detecção, em combinação com o uso de uma matriz de eventos críticos;

$\checkmark$ Algoritmos de correção de temperatura absoluta, para compensação da sensibilidade térmica.

\section{4 - Metodologia aplicada para validação do novo modelo de detecção de sticker.}

$\checkmark \mathrm{O}$ modelo termográfico foi instalado primeiramente off line, paralelo com o modelo de detecção residente na máquina três, a partir de Maio de 2016;

$\checkmark$ As placas com geração de alarme de sticker foram inspeciondas para identificar a veracidade do alarme e avaliar a necessidade de ajustes dos parâmetros do modelo;

$\checkmark$ Instalação do modelo termográfico on line após validação.

\section{RESULTADOS E DISCUSSÃO}

Os seguintes resultados de processo foram obtidos a partir de Maio de 2016, com a instalação do modelo termográfico no lingotamento contínuo no 3 (primeira fase):

$\checkmark$ Redução significativa da geração de alarme sticker quando comparado o modelo residente na máquina. A figura 9 mostra a estatistica destes alarmes. Como no periodo analisado, não houve nenhum rompimento de pele por sticker, conclui-se que este sistema é mais eficiente para redução de alarmes falsos contribuindo para redução dos custos de produção e aumento da qualidade do produto final.

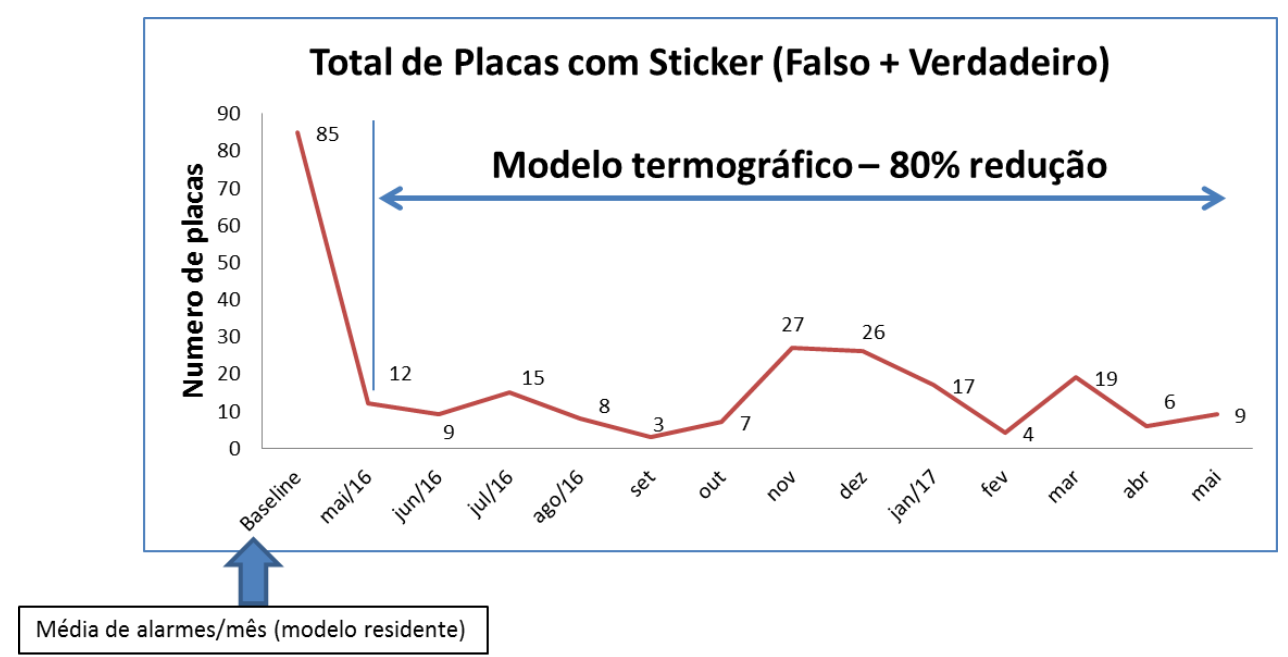

Figura 9. Frequência de alarme de sticker: modelo residente $x$ termográfico

$\checkmark$ Detecção efetiva de colamento do aço no molde (figura 10), com antecipação do alarme de 10 a 15 segundos antes do programa residente. 


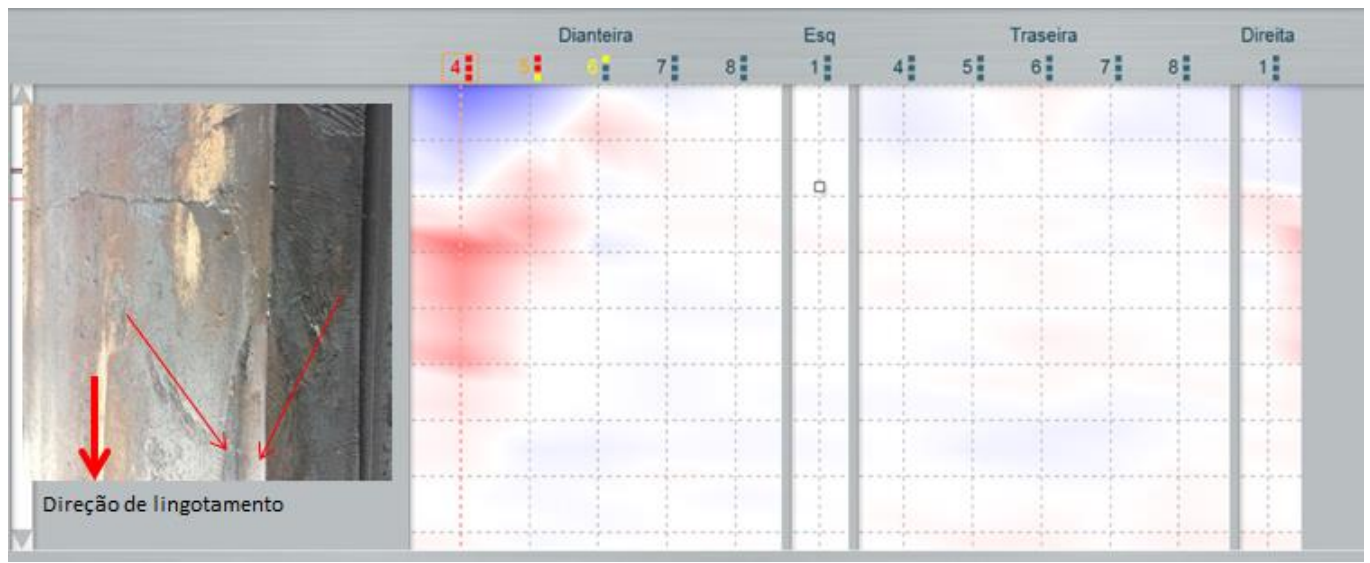

Figura 10. Validação do modelo termográfico em relação ao alarme de sticker

$\checkmark$ Durante o período de testes, que o modelo termográfico estava off line, houve uma ocorrência de rompimento de pele não detectado pelo modelo residente. O modelo termográfico detectou o colamento clássico no molde (figura 11).
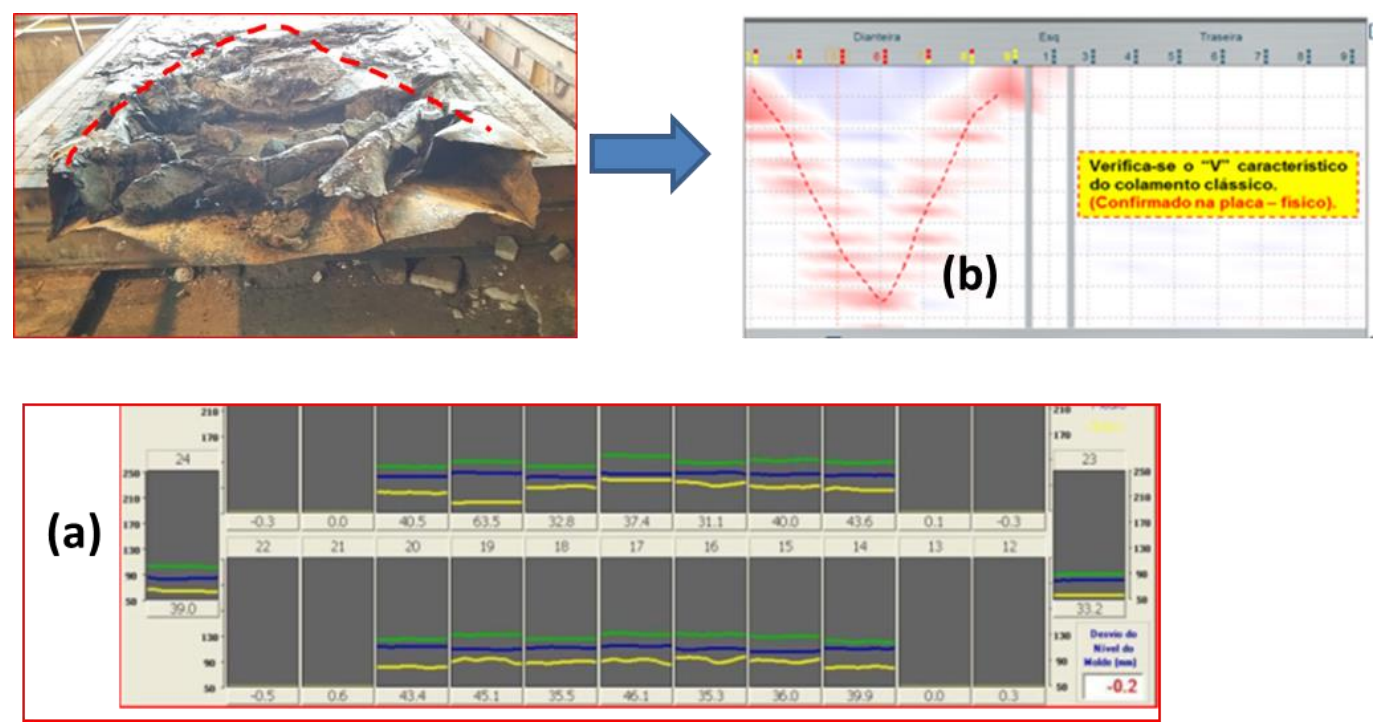

Figura 11. Ocorrência de breakout não detectado pelo modelo residente (a) e detectado pelo modelo termográfico off line (b). Aço médio carbono $(C=0,23 \%$ e $M n=1,30 \%)$

$\checkmark$ Através da imagem termográfica é possível identificar disturbios no molde tais como: obstrução do furo da válvula submersa com fluxo turbulento para um lado da face estreita, furo da válvula submersa e anomalias de fluxo de calor durante troca de largura.

\section{CONCLUSÃO}

O sistema termográfico, conjugado com o modelo de cálculo avançado, mostrou eficiência na detecção de verdadeiros stickers, reduzindo $80 \%$ os alarmes falsos no lingotamento contínuo III. Estes resultados contribuíram para reduzir os custos de processo, aumento da qualidade das placas e laminado a quente. 
Através da imagem termográfica permite visualizar de maneira efetiva todas as trocas térmicas anormais, incluindo o conhecido padrão de colamento no formato "V".

O modelo termográfico, conjugado com o modelo de cálculo avançado, foi implantado primeiramente no lingotamento contínuo III em Maio/2016 e na sequencia nos lingotamentos contínuos I e II - on line (Junho/ 2017).

\section{Agradecimentos}

Os autores agradecem a todos que contribuíram direta e indiretamente na elaboração deste trabalho, em especial às equipes de manutenção eletromecânica e operação.

\section{REFERÊNCIAS}

1 NASCIMENTO, A. D. et al. New Slab Technologies at ArcelorMittal Tubarão. In 6th European Contínuous Casting Conference, Riccione, Italy, 3-6/june, 2008.

2 ANDRADE, K.B. et al. Estudos sobre fatores causadores de colamento de aço no molde (sticker) e soluções adotadas para redução deste fenômeno. Contribuição Técnica ao XXXII Seminário sobre Fusão, Refino e Solidificação dos Metais, Salvador, BA, 07 a 09 de maio de 2001.

3 CASTIAUX,E; GRUENZNER,G. Breakout detection/prevention for slab and bloom caster. In 40th Steelmaking International Seminar, 24th - 28th of May 2009, São Paulo, Brazil. 